\title{
Experiences of Being Non-Smoking among Adolescents in a Smoking Context
}

\author{
Ingrid Edvardsson', Dorthe Geisler ${ }^{2}$, Lena Lendahls ${ }^{2,3}$ \\ ${ }^{1}$ Department of Clinical Sciences Malmö, Lund University, Lund, Sweden \\ ${ }^{2}$ Unit for Research and Development, Kronoberg County Council, Kronoberg County, Sweden \\ ${ }^{3}$ Department of Health and Caring Sciences, Linnaeus University, Kalmar, Sweden \\ Email: ingrid.edvardsson@ltkronoberg.se
}

Received 24 March 2014; revised 27 April 2014; accepted 6 May 2014

Copyright (C) 2014 by authors and Scientific Research Publishing Inc.

This work is licensed under the Creative Commons Attribution International License (CC BY). http://creativecommons.org/licenses/by/4.0/

(c) (i) Open Access

\begin{abstract}
Introduction: A study among Greenlandic 13-year-old showed that 68 percent for boys and 55 percent for girls, and at age 15, 46 percent of the boys and 32 percent of the girls were non-smokers. A literature review showed that the behaviour of parents and peers, attitudes and expectations were crucial factors for the smoking habits of adolescents. Young adults would more likely start smoking if their parents, older siblings and/or friends were smokers. Parental support has been proven to be a preventive factor against smoking, especially if the school and leisure centers get involved. Group pressure, directly or indirectly, is often described as the most important reason why adolescents start smoking. The purpose was to study why some adolescents choose to be smoke-free in a society where the norm is to smoke. Methods: Adolescents who were non-smokers were interviewed in focus groups. The material was analysed using content analysis. Results: The contents analysis of the text resulted in eleven categories. Based on these, four themes were developed. These themes covered areas on the reasons for being smoke-free; how the smoke-free adolescents generally felt about smokers from a society or environment perspective, and also specifically from an individual perspective, such as how smokers took up space and did not show any consideration. There was a feeling among non-smokers of not belonging and of ambivalence, as well as a perspective of the future for adolescents in Greenland and an uncertainty about what would be required for a smoke-free environment. Conclusions: In a context where the norm is to smoke, the adolescents need to make a conscious choice to be smoke-free, and there were different reasons for this choice. This choice means becoming an outsider in their group of peers as well as the overall social culture. Smokers were seen as taking up too much space, as their needs ruled and this was deemed inconsiderate.
\end{abstract}

\section{Keywords}

Adolescents, Greenland, Focus Group, Non-Smokers, Norms 


\section{Introduction}

Greenland is an arctic country, which previously was a Danish colony. Greenlandic is the official language, while Danish dominates in all higher education. Greenland has around 56,000 inhabitants and 89 percent of them were born in Greenland and 11 percent in Denmark. Around 16,000 live in Nuuk, which is the capital, and 32,000 in the 17 larger communities, most of them on the west coast. The remainder live in small villages with only a few people in each village [1].

Around 40 percent of all Greenland households have children under the age 18. About 75 percent of these live with both parents and 25 percent with one parent, mostly the mother. Teenage pregnancies are common and ca. 15 percent of all children have a mother who is under 20. Of the older school children, ca. 10 percent live with their grandparents. The children start school at age 6 and compulsory school is 10 years. In Greenland, there are major differences between urban and rural areas, but also between language groups regarding standard of living, education, income and health status. There are increasing reports of violence, accidents and suicide from eastern Greenland than those from Nuuk and the larger communities. Also, the education level is lower in rural areas compared to that in cities and towns, and of those who only speak Greenlandic, 64 percent have no higher education while the corresponding figure for Danish-speaking people is 17 percent [2].

A population study of life conditions, life style and health, which was done in Greenland in 2005 and 2007, showed that more than six of ten Greenlanders over 18 were smokers [3]. A new law on the prohibition against smoking in public places was introduced on October 1, 2010 in Greenland. The law aims to further health among the population and prevent people from involuntary exposure to the damaging effects of passive smoking [4].

Several school studies have shown that school children in Greenland have a high frequency of unhealthy habits of life. Around half of all 15-year-olds are smoking and ca. 80 percent have been drunk at least once, and many have also tried marijuana (40\%) and more than 75 percent have had sex. Compared to other European 15-year-olds, these are high figures. The prevalence of STD is also high and the incidence of chlamydia is highest among 14 - 19-year-old girls and 11 times higher than that in Denmark. Despite this, Greenlandic school children are more physically active compared to the rest of Europe, even though only half of them reach the recommended level of at least 60 minutes per day [5].

A study among Greenlandic 11 - 15-year-olds showed that 93 percent of both girls and boys were non-smokers at the age of 11 . At age 13, this figure was down to 68 percent for boys and 55 percent for girls, and at age 15, 46 percent of the boys and 32 percent of the girls were non-smokers. Looking at family structure, it was found that most of the non-smokers were pupils who lived with their biological parents and siblings, compared to pupils who lived in broken/new families ( $\mathrm{p}<0.0002)$. However, there were no differences depending on socioeconomic status [6].

Significant increases of non-smoking 13- and 15-year-olds were found among girls and boys from 1998 to 2006. Among 11-year-olds during this period, ca. 92 percent of the boys and ca. 87 percent of the girls were non-smokers, without any sign of a trend [7].

A study from 2008 on 517 Greenlandic upper secondary adolescents showed that 37 percent of the girls and 32 percent of the boys smoked on a daily basis. Of these, 61 percent of the girls and 71 percent of the boys would very much like to quit smoking [8].

A recent study showed that passive smoking was the largest risk factor for developing an ear infection (otitis media) among Greenlandic children. All of 42 percent of the mothers in the study were smokers, which shows the importance of preventive work among expecting and new parents to avoid that children are exposed to tobacco smoke [9].

A literature review by WHO showed that the behaviour of parents and peers, attitudes and expectations were crucial factors for the smoking habits of adolescents. Young adults would more likely start smoking if their parents, older siblings and/or friends were smokers. Parental support has proven to be a preventive factor against smoking, especially if the school and leisure canter's supports get involved. Smoking peers have much influence, as they often offer cigarettes to begin with in a way which creates a smoker behaviour which in turn creates norms with which adolescents identify. Group pressure, directly or indirectly, is often described as the most important reason why adolescents start smoking. Unfavourable life conditions, such as childhood violence or other adverse events are also associated with a higher risk of becoming a smoker. Most adolescents are able to describe the dangers with smoking, even though they underestimate them and do not realize their vulnerability. They focus more on the direct advantages than the long-term disadvantages. For example, they use smoking as a 
coping strategy to handle their daily stress, to get the courage to contact someone they like and especially among girls for weight control [10].

As far as we know, very little has been written about adolescents' experience of being smoke-free in situations where smoking is the norm.

\section{Purpose}

The purpose was to study why some adolescents choose to be smoke-free in a society where the norm is to smoke.

\section{Method}

\subsection{Study Population}

The study was performed in Greenland among students in upper secondary school. In total, there are three upper secondary schools, all with residential, and most of the students live there during the semesters. The students are representing both theoretical and practical programs. The smoke-free Greenlandic adolescents had grown up in a society where smoking was the norm. A majority of their parents are or have been smokers.

\subsection{Study Design}

Focus group interviews are defined as a scientific method where data is collected through group interaction on a topic decided by the scientist [11]. This method was selected for studying the contents, i.e. the views, attitudes, opinions, and arguments the participants expressed in a group. Focus group interviews will also give insight into the ideas and concepts used in a cultural context [12]. The method gives a variety of opinions as well as close contact with the smoke-free adolescents for increased knowledge without the purpose of reaching consensus or influencing them in any direction.

There are four upper secondary schools with 300 to 400 students per school in Greenland, and students from three of them were included in this study. The headmaster of the schools received instructions in writing of the aim and the selection. The participants were recruited through a contact person from the schools who had a relatively good knowledge of the students' tobacco habits. Inclusion criteria were that the participants not were smokers. Tobacco-free adolescents were invited into the study and received information in writing on the purpose of the group interview, on the procedure, and that all the material would be treated as strictly confidential. The adolescents gave written, informed consent to their participation. In total, 20 adolescents participated, aged 16 - 24, 4 boys and 16 girls, divided into three groups with six to eight students in each group. The groups were based on the respective schools and the participants knew each other to some extent. They were all recruited from upper secondary schools, such as natural sciences, technology, language \& humanistics, and social sciences.

The interviews were held in Greenlandic by one of the authors with Greenlandic as the mother tongue. One of the authors acted as moderator of the focus group discussions during the interviews. The role of the moderator was to be prepared to guide the discussions if the group deviated from the subject, ask clarifying questions when necessary, and ensure that all the participants got a chance to voice their views. The moderator was unknown to the participants. A guide with questions was developed with five different topics of interest: how they started smoking, circumstances that enabled the onset, students' views on prevention, attitudes to smoking and speculations about the future. Each topic had open questions and they were constructed based on earlier questionnaires. The interviews were conducted during school hours in a room at the students' schools and lasted about 90 - 120 minutes each. The interviews were transcribed ad verbatim in Greenlandic and were then translated into Swedish.

\subsection{Analysis}

Qualitative content analysis was carried out with an inductive approach according to the Graneheim and Lundman theory [13]. This meant that meaningful units were identified, condensed and coded into categories. These categories were grouped according to content to form themes. This method was selected in order to create a clear and manageable picture of the participants' experiences of being smoke-free in a context with a majority of smokers. The interviews were recorded on tape and transcribed verbatim and also translated into Swedish. The 
material was read through a number of times to catch the overall feeling by the tree authors. To be true to the context, the meaningful sentences were condensed to a description close to the text, the manifested content, as well as an interpretation of the underlying meaning, the latent content. To enable processing of the text, the analysis was done in different steps. Firstly, meaningful units from all interviews were identified, and these were then condensed and coded and finally put together into different categories. One of the authors conducted the interviews and all authors analysed the text, independent of each other, and then the different steps of the analysis were discussed until consensus was reached. An example of the analysis process is shown in Table 1. To clarify the results, three themes were crystallized to a more abstract level on the basis of the categories. Representative quotations are presented in italics and the group origin is presented in brackets.

\section{Findings}

The contents analysis of the text resulted in eleven categories. Based on these, four themes were developed (Table 2). These themes covered areas on the reasons for being smoke-free, how the smoke-free adolescents generally felt about smokers from a society or environment perspective, and also specifically from an individual perspective, such as how smokers took up space and did not show any consideration. The theme of a feeling of not belonging as a non-smoker and the ambivalence, as well as the perspective of the future and what would be required for a smoke-free environment and adolescence in Greenland.

\section{Reasons for Being and Staying Smoke-Free}

Most adolescents said they had tried smoking with initiated friends. It is easy to get access to cigarettes and smoking friends were happy to introduce you to smoking as a pleasure for everybody—like an initiation into the adult world.

The adolescents said that one of the reasons for being smoke-free was that smoking did not start well. Reasons mentioned were coughing, the cigarette tasted and smelt disgusting and that the smell stuck to your hair and clothes. Some said it did not suit their personality as doing sports.

Some adolescents had relations who had died from lung cancer, and they had realized that smoking may lead to death and other illnesses such as asthma. Someone did not understand why it was even allowed to buy cigarettes in the country. They all mentioned the drawbacks of smoking: smokers had poor health, easily caught colds, the lungs deteriorated over time and they were less fit. One of the adolescents had discovered that the

Table 1. Example of the analysis process.

\begin{tabular}{ccc}
\hline \multicolumn{1}{c}{ Meaningful unit } & Condensation & Code \\
\hline $\begin{array}{c}\text { Yes, they take up so much space, you know, just } \\
\text { through the smoke or the smell of smoke. It's as } \\
\text { if there is no room for the rest of us. }\end{array}$ & $\begin{array}{c}\text { Smokers take up so much space } \\
\text { through smoke and smell. There } \\
\text { is no room for the rest of us. }\end{array}$ & $\begin{array}{c}\text { Smokers take up space } \\
\text { Attitudes to } \\
\text { smokers }\end{array}$ \\
\hline
\end{tabular}

Table 2. The eleven categories and four themes in the analysis.

\begin{tabular}{|c|c|}
\hline Categories & Theme \\
\hline Reasons for being smoke-free & Reasons/incentives for being and staying smoke-free \\
\hline \multicolumn{2}{|l|}{ Advantage of being smoke-free } \\
\hline \multicolumn{2}{|l|}{ Inner conviction (active choice) } \\
\hline Smoker influence & How smokers are perceived \\
\hline \multicolumn{2}{|l|}{ Attitudes to smokers } \\
\hline \multicolumn{2}{|l|}{ Smoker behaviour } \\
\hline \multicolumn{2}{|l|}{ Smoking gives advantages } \\
\hline Smokers’ community & Being a non-smoker-an outsider \\
\hline \multicolumn{2}{|l|}{ Ambivalence } \\
\hline Prevention & Dream of the future-smoke-free life in Greenland \\
\hline Norm & \\
\hline
\end{tabular}


walls in her grandmother's house were yellow due to indoor smoking.

Nearly all the adolescents said that smoking changed your looks as smokers aged faster with wrinkles, dark rings under the eyes, ugly skin and yellow, bad teeth. They also said that smoking made your sense of smell worse.

Other reasons for being smoke-free were smoke-free parents as role models that they wanted to be role models for their future children, or their experience of smoking with poor health and addiction.

My dad has never smoked and I have always looked up to him, and I think it's thanks to him that I don't smoke.

The adolescents saw many advantages of being smoke-free. Primarily, they noted a difference in terms of looking healthy, and that non-smokers dressed smarter. Non-smokers felt they were more mature than the smokers.

I have noticed that mature people don't smoke, and I think they look healthier; have smarter clothes [...] while the smokers have red noses and look less healthy and simply uglier.

Many decided already as children that they would never start smoking, a promise or conviction that was strong as the temptation to start smoking was apparent in their environment.

The perspective for the future as a non-smoker was strong among many adolescents, and the disadvantages of smoking were many, and they could not see themselves as tied to a "vice" with so many health issues in the future. Furthermore, they saw themselves as role models to others, and they were proud of this. It was important to be able to influence people around them by being smoke-free, something they saw as a mission. They felt that many children and adolescents did not think of the consequences.

We must start with the adolescents, and maybe this will stop many of them from starting to smoke. You can show examples of what non-smoking adolescents have achieved compared to those who smoke.

\section{How Smokers Are Perceived}

This theme deals with how the interviewed pupils generally saw the smokers, both from a society or environment perspective, and also specifically from an individual perspective, such as how smokers took up space and did not show any consideration.

The adolescents felt that as most people in Greenland are smokers, you are among smokers most of the time, and that makes it easy to start smoking without considering the consequences. And if the parents tell their children not to smoke, but smoke themselves, this gives contradictory and double messages.

Most people smoke here and you are influenced to start without thinking of the consequences.

It is difficult to withstand peer pressure as you want to belong to the group and be accepted. It is particularly difficult at parties when cigarettes are offered and the smokers are happy to teach others how to take a deep drag. Many students may be non-smokers when they start upper secondary school, but they are smokers when they finish school.

All my friends were smoking and I was on my own, so I started smoking as well and became addicted...

Love was another reason for starting to smoke. If you were in love with a boy or a girl who was smoking, you wanted to be like him or her. Even of it tasted badly to begin with, you practiced and finally became a smoker, but by then the relationship could be over.

When I started smoking as a 14-year-old, the person I was in love with was smoking and to show...

During school hours, the non-smokers felt they had nowhere smoke-free to be. Even though it was prohibited, people were smoking just outside the door, especially when it was cold outside. Then, the entire corridor was smelling of smoke.

We moved the bench away from the entrance, but they had moved it back already the next day. They don't respect us at non-smokers at all but only think of themselves.

One of the adolescents noted that "cool” celebrities were important role models, but there was great disappointment when a paparazzi photo showed that she was actually a smoker.

The interviewed adolescents agreed that smokers took up space and did not show enough respect for nonsmokers, and this was mostly caused by the fact that the norm was to smoke. One of the expressions of this was that they smoked indoors and at entrances without caring that all passers-by were exposed to smoke and smell. Many adult smokers were seen as careless and egoistic and only thinking of themselves and not how they intruded into other people's lives.

I respect other people who have elected to smoke, but if it affects my live, I want them to respect me as well 
and not smoke outside the school entrance, for example.

It was also said that smokers thought they were cool when they smoked, when it in fact was "un-cool" to smoke. It was difficult to understand why they were doing something so pointless as to smoke. However, they also understood that many people used the cigarette as a problem solver, and also that the smokers often had social problems.

People start smoking because of problems they cannot solve, and instead they escape it by smoking.

Furthermore, many smokers seem to think they get warm by smoking, when science in fact says it is the opposite.

Someone said she had to "be mother" for her sister's children as she felt her older sister prioritized the cigarettes before her children.

Smoking during pregnancy was said to be the height of egoism as the unborn child was exposed to damages at a fetal stage and later in life as well. Many young girls have babies and seeing them smoke was very tiresome. It was also considered crazy that so many breastfeeding women were smoking, as the nicotine is transferred via the breast milk and consumed by the baby. Mothers who smoked when they were out walking with a pram were not liked either.

I think it is very egoistic that they smoke when they are pregnant. It's as if they don't love their child more than the drug.

They also felt that smokers had a poorer sense of smell as they did not sense that cigarette smoke smelt bad. This is something they only noticed when they had quit smoking, or tried to quit smoking and the sense of smell came back.

Those who smoked a hookah seemed to think this was a healthier alternative than cigarette smoking as it did not smell and you had to inhale several times before you got the desired effect.

There were smokers, though not many, who were considerate and smoked outdoors when they were at a party. As the consequences of smoking were known, primarily on health, they wished and hoped that as many people as possible would quit smoking, but that it was not enough to tell them.

When you see smokers, you wish and hope that they would quit, but words are not enough.

The adolescents interviewed pointed out that smokers were ruled by the cigarettes and often used them as problem solvers. They smoked when they were stressed, felt depressed or lonely, or had nothing to do. Instead of dealing with their problems or find things to do, they lit a cigarette. As non-smokers, they would like to tell them that it was a bad way of tackling their problems, and that they should think of their bodies. At the same time, they felt everyone was responsible for his/her own body.

I also have a friend who smokes as soon as she's not happy, and instead of tackling the problems directly, she smokes... and that's not good.

They also felt that most smokers did not seem to be aware of their behaviour, as then they would not sit there smoking right beside the entrance of the school or under a window. If you opened a window to let in some fresh air, smoke came in instead. The teachers also stank of smoke when they came in from a break, and the entire classroom smelt of smoke.

We have teachers who usually smell very much of smoke when they enter the classroom.

They were also annoyed that the smokers threw their butt-ends everywhere so they had to see them littering the streets. When they had cleaning days in school, most of the rubbish was butt-ends.

I don't like it that we have to collect all the butt-ends when we have not been part of the littering.

Another thing they had noticed was that most smokers had a weaker economy than they had, as they spent their money on cigarettes. This meant that they were not able to shop or travel to the same extent.

You save money when you don't smoke, and you can afford to travel to other countries and buy an expensive camera.

Another thing was that the smokers got extra breaks as it was considered OK to take a smoking break. One girl said that her boyfriend, who did not smoke, was told to work while his workmates took a 15 minute smoking break. She thought this was unfair.

Informants felt that smokers must change their behaviour and stop subjecting others to passive smoking. The reason for this was that passive smoking could even be more dangerous that smoking. It could cause asthma among children and even cancer among adults, as well as nicotine discolouring and smelly clothes. Tobacco smoke could also cause red and runny eyes.

You may get lung cancer, and it is so sad that the clothes smell of smoke. 
They could understand that smoking had some advantages, such as belonging to a group. To get together and smoke at the breaks created some sense of security. Also, there was a "smoking house" in the school yard where you could be when the weather was bad. Another advantage was the stress relief effect the cigarettes could have.

Many adolescents get together in a group and smoke.

\section{Being a Non-Smoker-An Outsider}

As a non-smoker, the adolescents felt like outsiders when they were not part of the fellowship the smokers had. The adolescents felt that many became smokers because they wanted to be part of this fellowship. The nonsmokers felt lonely and were drawn to other non-smokers in order not to be outsiders. Whether a person was smoking or not was the deciding factor for being together-more than interests or personal characteristics.

When we started in $1 \mathrm{G}$, I noticed that several of my classmates went out to smoke, and I was thinking who will be my friend when they are all smokers... but I was lucky to find a friend who did not smoke... but in the beginning it was hard to find friends as they all went out to smoke... it was no doubt a problem when you were not a smoker yourself.

Among some non-smokers, there was ambivalence with regard to their smoke-free future. They expected to be non-smokers, but still thought that they would maybe try smoking in the future.

I expect to be a non-smoker... but realistically I count on trying it again.

Hookah smoking was considered OK if you did it occasionally, and it was fun when there were a few of you who experienced a fellowship when participating in these activities.

\section{Dream of the Future-Smoke-Free Life in Greenland}

The adolescents were aware of both the importance of the social environment for smoking and that the prevailing norm in Greenland was smoking. To change attitudes and norms, many changes are needed.

The adolescents felt that politicians, teachers and parents have a responsibility to reduce smoking among adolescents. More strict legislation, price increases on cigarettes and more smoke-free environments were some ideas to make the population more smoke-free. Older people, who started smoking way back in time, were influenced by the commercials of the time saying how glamorous it was. Nowadays, advertising has been replaced by information on the cigarette packets on how dangerous it is to smoke. They were thinking that maybe this can have the effect that fewer people start smoking.

If more environments are smoke-free, being a non-smoker becomes more visible and they can become increasingly more.

Teachers were seen as role models who should not smoke with the pupils, as this gives the wrong signals.

After the English classes last year, the teacher joined the smokers at the breaks outside and chatted with them. When teachers do this, they tell the pupils that smoking is OK.

Parent importance was often noted, both as smoke-free role models for their children but also what they said to their children affected whether they became smokers or not. The adolescents felt that parents were not credible if they smoked and still told their children not to start smoking. When the children saw their parents smoking as they grew up, it also became natural to smoke and the norm was confirmed.

Also, the adolescents had many ideas on how the environment could be more smoke-free. Smoking was seen as contagious and it was desirable that more people were smoke-free. Many of them wanted the influence to go the other way, that smokers were influenced by the non-smokers and thereby changed the norm. It would only then be possible to see a change. Those who were smoke-free felt that the smokers showed them no consideration, while the smokers felt discriminated against if they were reminded that they should not smoke at restaurants, for example:

I usually hang out with non-smoking friends, because I know that if my friends don't smoke it's easier to say no to cigarettes.

I think smokers are shown too much consideration in this country, and they are forgetting that there are also lots of non-smokers.

\section{Discussion}

\subsection{Methods Discussion}

Focus group interview is a qualitative research method, which is used for collection of data on attitudes, experi- 
ences and opinions of groups [14]. Through the interviews, knowledge was acquired from discussions between adolescents, who were given the opportunity to describe and discuss their experiences of being smoke-free in their own words. The method gave insight into what it is like to be a smoke-free in a context when the majority are smokers. Since focus group interviews rely on discussions among participants, group members may influence each other as to how they respond to ideas and comments that arise during the discussion [12]. However, it is important to bear in mind that data acquired from a focus group are group data, which reflect the collective ideas shared and talked about by the group. In a focus group, the participants are in a more natural environment than during individual interviews. They are together with their friends and can both influence and be influenced by each other, which is what happens in real life [12].

A strong point in this study is that the person who conducted the interviews spoke the native language and was familiar with the culture. One weakness was that the interviews had to be translated into Swedish for the analysis. However, the translator was fluent in both languages and we consider it a very small risk that any information was lost in translation.

\subsection{Results Discussion}

As far as we know, there are no qualitative studies where adolescents were interviewed on their experience of being smoke-free in a context where the majority is smoking. The experiences and perspectives of smoke-free adolescents are important to the development of tobacco prevention work in the future, as most of the scientific studies highlight the experiences of smokers [15]. The adolescents live in a cultural and social environment which is well-known to them and they are very familiar with the applicable norms and conditions.

The smoke-free adolescents had made a conscious and active choice not to be smokers. Despite the fact that most of the adolescents had a strong conviction about not smoking, most of them had been unable to resist the group pressure and had tried it. Eventually, however, their own convictions and norms they primarily acquired from their homes took over, and they decided not to smoke. Other reasons for being smoke-free were health aspects, fitness and looks, and they are all in line with previous research [16].

The smoke-free adolescents had a condescending attitude to their smoking friends. They felt they were lacking of an insight into what they were doing, they were seen as egoistic and showed no consideration for the nonsmokers or prevailing regulations. And they were very upset about pregnant women and mothers with newborns smoked. This was seen as the height of selfishness. There was a lack of insight into the problem of addiction, even if they understood that smoking was a way to handle difficult times in life. A similar attitude was found in a study of how adolescents using snus saw smokers [17].

Adolescence is a time when you "become somebody" and develop in a social context. Teenage hood is a time full of complex and contradictive feelings. The group of friends has an important role in a young person's life and the group norms, attitudes and behavior has a larger impact on the youth. There are several studies showing that adolescents' perception of their friends and their own social identity is related to their use of tobacco [18]. This study shows that the adolescents had a strong identity, which was linked to them being smoke-free, something they stood up to despite the discomfort of not being like the majority.

The study shows that non-smoking adolescents were actively seeking to be friend other adolescents who were also smoke-free. To be smoke-free was a crucial characteristic for finding "my" group and feel fellowship. They did not choose each other on the basis of interest or other characteristics, but the very fact that they did not smoke. They felt a lot of things revolved around the smoking, where you went and who you spent time with, and the fellowship was based on smoking habits. Therefore, smoking was the norm, and if you did not follow this norm, you were considered different and became an outsider. Smoking appears in a social context where a person is part of a group of friends and is affected by them. Adolescents value friendship very highly and are eager to fit into a group, and they are strongly affected by the group members. Adolescents select friends with similar attitudes and behaviour regarding smoking as themselves [19]. It happened also that smoke-free pupils became outsiders when teachers smoked with the pupils. The smoke-free pupils felt that the smokers had a different and perhaps better contact with the teachers when they were smoking together.

The norm in the society results in an early smoking debut, which makes it more difficult to quit. According to a study in Greenland, up to 65 percent of the smoking said that they wanted to quit smoking, which is a high figure compared to Sweden, for example [8] [20]. The adolescents interviewed had several ideas on what had to be done to make more of them smoke-free. One aspect had to do with activities at society level, such as stricter legislation, which has been partly introduced after the study was done and smoke-free environments were intro- 
duced (legislation). Another thing considered effective would be price increases on cigarettes. According to WHO recommendations, these are activities which are crucial to a reduction of smoking [21] [22]. Other proposals brought forward were recurrent anti-smoking campaigns and offers of anti-smoke cures at the workplace. At the same time, there is a feeling of impatience that changes are too slow and that there is a long way to go when it comes to changing the prevailing norms.

Even if the results may primarily be seen as transferable to the Greenlandic context with a geographically small and partly secluded country, adolescents think in similar ways regardless of where they live.

The fact that there are many adolescents in Greenland who say that they want to quit smoking, this should be an incentive for further studies to gain knowledge on what is needed to take the step towards becoming smokefree. It would also be interesting to interview teachers to find out how they view their responsibility for pupils remaining or becoming smoke-free.

\section{Conclusion}

In a context where the norm is to smoke, the adolescents need to make a conscious choice to be smoke-free, and there were different reasons for this choice. This choice means becoming an outsider in their group of peers as well as the overall social culture. Smokers were seen as taking up too much space, as their needs ruled and this was deemed inconsiderate.

\section{References}

[1] The Data Bank (2012) Statistics Greenland Population in Municipalities. http://www.stat.gl/

[2] Niclasen, B.V. and Bjerregaard, P. (2007) Child Health in Greenland. Scandinavian Journal of Public Health, 35, 313322. http://dx.doi.org/10.1080/14034940600975781

[3] Bjerregaard, P., Ik, D.-P. Befolkningsundersögelsen i Grönland (2005-2007) Levevilkår, livsstil och helbred. Syddansk Universitet, Statens Institut for Folkesundhed, Köpenhamn, 2008.

[4] Inatsisartutlov nr. 15 af 26 maj 2010 om forbud mod rygning (2010).

[5] WHO (1998) Health among Young People Health and Health Behaviour WHO Policy Series: Health Policy for Children and Adolescents Issue 1. WHO, Copenhagen.

[6] Granado Alcon, M.C. and Pedersen, J.M. (2001) Family as a Child Development Context and Smoking Behaviour among Schoolchildren in Greenland. International Journal of Circumpolar Health, 60, 52-63.

[7] Niclasen, B. and Schnohr, C. (2008) Has the Curve Been Broken? Trends between 1994 and 2006 in Smoking and Alcohol Use among Greenlandic School Children. International Journal of Circumpolar Health, 67, 299-307. http://dx.doi.org/10.3402/ijch.v67i4.18344

[8] Niclasen, B. and Hansen, H. (2008) YOU—Unges sundhed i Grönland 2008. Sundhed, Sundhedsad faerd og holdninger blandt gymnasieelever på skolenavn. Syddansk Universitetet, Institut for Virksomhedsledelse og Ekonomi, Laegerklinikken.

[9] Jensen, R.G., Koch, A., Homoe, P. and Bjerregaard, P. (2013) Tobacco Smoke Increases the Risk of Otitis Media among Greenlandic Inuit Children While Exposure to Organochlorines Remain Insignificant. Environment International, 54, 112-118. http://dx.doi.org/10.1016/j.envint.2013.01.015

[10] Currie, C. (2012) Social Determinants of Health and Well-Being among Young People. Health Behaviour in SchoolAged Children (HBSC) Study International Report from the 2009/2010 Survey. WHO Regional Office for Europe, Copenhagen.

[11] Morgan, D.L. (1997) Focus Groups as Qualitative Research. 2nd Edition, Sage, Thousand Oaks, viii, 80.

[12] Kreuger, R.A., Casey, M. and Focus Groups (2000) A Practical Guide for Applied Research. 3rd Edition, California Sage Publications Inc., Thousand Oaks.

[13] Graneheim, U.H. and Lundman, B. (2004) Qualitative Content Analysis in Nursing Research: Concepts, Procedures and Measures to Achieve Trustworthiness. Nurse Education Today, 24, 105-112. http://dx.doi.org/10.1016/j.nedt.2003.10.001

[14] Kitzinger, J. (1994) The Methodology of Focus Groups: The Importance of Interaction between Research Participants. Sociology of Health \& Illness, 16, 103-121. http://dx.doi.org/10.1111/1467-9566.ep11347023

[15] Nilsson, M., Stenlund, H., Weinehall, L., Bergstrom, E. and Janlert, U. (2009) I Would Do Anything for My Child, Even Quit Tobacco: Bonus Effects from an Intervention That Targets Adolescent Tobacco Use. Scandinavian Journal of Psychology, 50, 341-345. http://dx.doi.org/10.1111/j.1467-9450.2009.00716.x 
[16] Edvardsson, I., Lendahls, L. and Hakansson, A. (2009) When Do Adolescents Become Smokers? Annual Seven-Year Population-Based Follow-Up of Tobacco Habits among 2000 Swedish Pupils-An Open Cohort Study. Scandinavian Journal of Primary Health Care, 27, 41-46. http://dx.doi.org/10.1080/02813430802588675

[17] Edvardsson, I., Troein, M., Ejlertsson, G. and Lendahls, L. (2012) Snus User Identity and Addiction. A Swedish Focus Group Study on Adolescents. BMC Public Health, 12, 975. http://dx.doi.org/10.1186/1471-2458-12-975

[18] Sussman, S., Pokhrel, P., Ashmore, R.D. and Brown, B.B. (2007) Adolescent Peer Group Identification and Characteristics: A Review of the Literature. Addictive Behaviors, 32, 1602-1627. http://dx.doi.org/10.1016/j.addbeh.2006.11.018

[19] de Vries, H., Candel, M., Engels, R. and Mercken, L. (2006) Challenges to the Peer Influence Paradigm: Results for 12-13 Year Olds from Six European Countries from the European Smoking Prevention Framework Approach Study. Tobacco Control, 15, 83-89. http://dx.doi.org/10.1136/tc.2003.007237

[20] Statens Folkhälsoinstitut (2010) Tonåringar om tobak: Vanor, kunskaper och attityder. Statens Folkhälsoinstitut, Stockholm.

[21] World Health Organization (2010) WHO Technical Manual on Tobacco Tax Administration. World Health Organization, Geneva.

[22] Pierce, J.P., White, V.M. and Emery, S.L. (2012) What Public Health Strategies Are Needed to Reduce Smoking Initiation? Tobacco Control, 21, 258-264. http://dx.doi.org/10.1136/tobaccocontrol-2011-050359 